\title{
Preparation and Characterization of Ti/rGO- $\mathrm{RuO}_{2}$ Electrode for Hydrogen and Oxygen Evolution Reactions
}

\author{
Xiaoyang Bao, Jiqing Bao* , Jie Xu, Cong Xu \\ School of Biological and Chemical Engineering, Jiaxing University, Jiaxing 314001, China; \\ *E-mail: $469784902 @$ qq.com
}

doi: $10.20964 / 2018.08 .45$

Received: 11 May 2018 / Accepted: 15 June 2018 / Published: 5 July 2018

This paper presents a preparation method of a graphene $\mathrm{RuO}_{2}$ composite electrode. The electrode is obtained via electrochemical reduction of graphene oxide (GO) on a Ti substrate followed by thermal decomposition to prepare $\mathrm{RuO}_{2}$. According to results from SEM, CA curves, and EIS impedance, $\mathrm{Ti} / \mathrm{rGO}-\mathrm{RuO}_{2}$ has many exposed active sites and good electrical conductivity. Ti/rGO-RuO $\mathrm{O}_{2}$ also shows excellent electrocatalytic performance for electrochemical water splitting (hydrogen evolution potential is $-1.226 \mathrm{~V}$ and oxygen evolution potential is $0.842 \mathrm{~V}$ ). After $10 \mathrm{~h}$ of electrolysis at 250 $\mathrm{mA} \cdot \mathrm{cm}^{-2}$, the activity of $\mathrm{Ti} / \mathrm{rGO}-\mathrm{RuO}_{2}$ showed no significant decrease for the hydrogen evolution reaction. In sum, Ti/rGO- $\mathrm{RuO}_{2}$ contains an intermediate layer of graphene, has excellent application prospects in electrochemical water splitting, and has good application value in the field of hydroelectricity.

Keywords: metal oxide anode; graphene; water splitting

\section{FULL TEXT}

(C) 2018 The Authors. Published by ESG (www.electrochemsci.org). This article is an open access article distributed under the terms and conditions of the Creative Commons Attribution license (http://creativecommons.org/licenses/by/4.0/). 